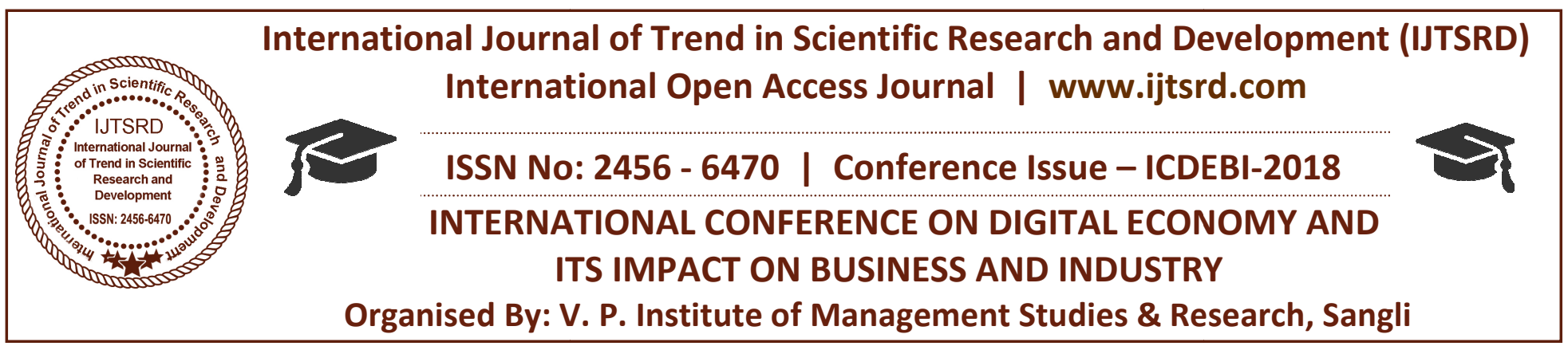

\title{
Applicability of ERP in Indian Small and Medium Enterprises
}

\author{
Dr. Abhijeetsinh Jadeja ${ }^{1}$, Jaimini Kulkarni ${ }^{2}$ \\ ${ }^{1}$ Assistant Professor, ${ }^{2}$ Research Scholar \\ ${ }^{1}$ B. P. College of Computer Studies, KSV University, Gandhinagar, Gujarat, India \\ ${ }^{2}$ BAOU University, Ahmedabad, Gujarat, India
}

\begin{abstract}
ERP (Enterprise Resource Planning) may be thanks to integrate the information and processes of a corporation into one single system. Its main goal is to integrate knowledge and processes from all areas of the organization and unify it, to supply easy access And an economical work flow. ERP Systems typically accomplish this through one single info that employs multiple software package modules. In India, SMEs area unit the backbone of the economy and area unit nowadays baby-faced with world competition. Therefore, it becomes imperative to appear for means that of responding to the dynamic markets. ERP systems became the foremost common IT strategy for many giant corporations. Gift analysis argues that ERP implementation in Indian SMEs ought to extend its scope on the far side the configuration to the strategic, managerial, and technical and structure problems by considering vital success factors for flourishing ERP implementation at Indian SMEs that will place Indian SMEs on the competitive position. During this paper, we've got examined ERP in Asian nation.
\end{abstract}

\section{KEYWORDS: SME.}

\section{INTRODUCTION}

ERP (Enterprise Resource Planning) may be an outcome of knowledge Technology and is a thanks to integrate the information and processes of a corporation into one single system, exploitation subsystems that embrace hardware, software package and a unified info so as to attain integration, to store the information for numerous functions found throughout the organization. The term ERP won't to refer concerning however giant organizations of the commercial kind planned to use structure wide resources. nowadays ERP is employed in nearly any variety of organization it does not matter whether or not it's giant, little or what trade it falls in. however will we understand what software package will be thought of ERP? 1st, it should give a corporation with practicality for a minimum of 2 systems or additional. However, several of today's ERP systems will cowl quite simply 2 functions and integrate them into one unified knowledge Base. Human Resources, offer Chain Management, client Relations Management, Financial, producing functions and Warehouse Management functions will be found on trendy corporations underneath one umbrella - the ERP system.[1][15][21] The Key to ERP is integration. Its main goal is to integrate knowledge and processes from all areas of the organization and unify it, to supply easy access and an economical work flow. ERP Systems typically accomplish this through one single info that employs multiple software package modules. the perfect configuration is then to possess one ERP system for a whole organization, however organizations that area unit terribly giant are illustrious to form AN ERP system and so add external interfaces for different stand alone systems thought of additional powerful or ready to fulfill the organization's wants in a very higher means. Recently the ERP vendors have developed and customized the ERP software package for the employment of every kind of industries.[3][11][28] This has created an excellent demand on the employment of ERP among business entities to integrate and maximize their resources. The growing demand for ERP applications among business corporations has many reasons • Competitive pressures to become a coffee value 
producer. - to extend the revenue growth. - Ability to contend globally. $\bullet$ maximising the resources and also the want to re-engineer the business to reply to plug challenges (Gattiker and Goodhue, 2005).[7][25]

\section{LITERATURE REVIEW}

This space has been subjected to a major quantity of previous analysis. Many approaches are taken. Slevin (1987) originally projected $10 \mathrm{CSFs}$ for project management. Their work was engineered upon by The Netherlands (1999). They divided the implementation method into strategic and military science subgroups, adding factors specific to software package comes. the appliance and modification of existing project management techniques to ERP was conjointly selfaddressed by Edward Weston (2001), WHO conjointly thought of the problems encompassing the event stages that the project passes through, associated metrics, and also the software package employed in ERP implementations. These problems are more investigated by different researchers. Notably Ahituv et. al., (2002) WHO investigated systems development methodologies for ERP systems, whereas Huang et al., centered upon the requirement for organizations to form a repository of implementation best follow to make sure consistency across ERP implement (Huang,2004). Zviron et al., thought of the problems encompassing the measure of user satisfaction and perceived utility within the ERP context (Zviran, 2005). Whereas Sumner (1999) thought of implementation problems through series of ERP case studies leading to a collection of tips designed to push success in giant software package project implementations. Nah, Lau and Kuang (2001) undertook a literature search of ERP implementations and known eleven CSFs and regarded their relationship to Markus and Tanis's process-orientated ERP Life cycle model (200). Bajwa ANd Garcia (2004) developed an integrative framework for the assimilation of ERP systems, extending the literature within the space of vital extenal antecedents, whereas Gulledge and Sommer (2004) examined the problems encompassing scoping business processes once rending SAP instances. Parr and Shanks (2003) engineered on their earlier analysis into CSFs, characteristic 10 sanctionative factors, then exploitation more case analysis to construct a project part model for ERP implementation. Meantime a cogent study by Somers and Horatio Nelson (2001) conjointly the literature for CSFs and took Cooper and Zmud's six stages IT implementation method model (1990) as a basis for ranking and categorise them by stage. The Somers Horatio Nelson CSF classification was extended by Akkermans and van Helden WHO, through the appliance of a longitudinal case study, showed that interdependencies each indirect and direct exist within the success factors and significantly that 'they all influenced one another within the same direction i.e., all positive or negative, resulting in a self perpetuating or cycle of fine or poor performance' (2002). analysis has conjointly been undertaken on subsets of CSFs classifications; for instance, Sarker and Lee (2003) examined 3 major social enablers in ERP implementations, whereas Gefen (2004) thought of the problem of trust between vendors ANd shoppers inside ERP implementations and Luo and powerful projected a framework for evaluating implementation selections touching on the customization of an ERP ( Luo, 2004).

\section{CHALLENGES IMPLEMENTATION}

ERP

A lot of companies within the developing countries face varied challenges in implementing technologies like Enterprise Resource coming up with (ERP) systems, together with an absence of human and money resources to support such initiatives (Wright et al., 2002). What is more, the government's commitment to the event of technology infrastructure can even be seen from the Indian Industrial program from 2006-2020, coinciding with the country's vision for 2020. [4] for instance, the govt has enforced varied policies and methods below this arrange that was developed to reinforce the expansion of the industries through the complete price chain and to encourage cluster primarily based industrial development. But numerous studies have discovered that not all ERP implementations ar roaring in rising the productivity and competencies of an organization. consistent with Gattiker and Goodhue (2005), ERP implementation failure rate is from four-hundredth, however firms attempt to implement these systems as a result of they're absolutely essential to responsive coming up with and communication.[5][19] The competitive pressure unleashed by the method of economic process is driving implementation of ERP comes in more and more massive numbers, thus a method framework for managing complicated problem of evaluating ERP comes is needed. it's been found that, distinctive risks in ERP implementation arises thanks to tightly connected interdependencies of business processes, relative databases, and method reengineering (Wright and Wright, 2002). Consistent with Gordon (2006), 3 main factors which will be 
command answerable for failure of ERP system are • poor coming up with or poor management • amendment in business goals throughout project • lack of business management support. In another study, it's been found that firms spent massive cash in developing ERP systems that aren't used. From a software system perspective ERP systems is complete. However from the business perspective it's found that software system and business processes ought to be aligned, that involves a mix of business method style and software system configurations (Mabert et., 2003). Thus a strictly technical approach to ERP system style is meager. consistent with Gordon (2006), a careful use of communication and alter management procedures is needed to handle the usually business method reengineering impact of ERP systems which may alleviate a number of the issues, however a a lot of elementary issue of concern is that the price feasibleness of system integration, coaching and user licenses, system utilization, etc. ought to be checked. A style interface with a method arrange is a necessary a part of the system integration method in ERP.[6][8][29]

\section{OBJECTIVE OF STUDY}

The primary objective of this analysis is to look at the vital success factors of ERP implementation to attenuate the ERP implementation failure rate among the native firms. The analysis was centered in several sectors of the economy. Except for that the study additionally aimed to spot the ERP usage contribution to the business performance of the organizations. ERP implementations completed between 1995 and 1998 in Asian country will provides a sense of specific hurdles that firms could encounter in ERP preparation. Many firms were surveyed, and diverse ERP professionals were interviewed so as to assess the state of ERP in Asian country. The results indicate that Indian firms are moving forward with ERP implementation primarily in response to thrusts from parent collaborators, to revamp so as to fulfill redoubled load, or to scale back lead times and inventory levels, and improve client satisfaction. Resistance to vary was a significant hurdle featured throughout several ERP implementations. in addition, the duplication needed within the initial stage, and also the intense pressure exerted on force proven to be problematic, as did the extent of customization necessitated by disparities between company needs and solutions offered by ERP software system. This downside is decreasing thanks to advances within the software system facility models. [9][14][17] Price overruns additionally proven to be a pervasive downside with ERP implementations. To avoid this downside, prime management should develop the mandatory commitment to ERP, and every one worker ought to be ready for the amendment before the ERP implementation method is started. This model ought to facilitate to eliminate unnecessary project time and price flying. [5][10][24]

\section{ERP IN INDIA}

Some of the primary Indian firms to possess adopted ERP practices square measure HLL, ONGC, ESSAR, Godrej Soaps, Cadburys, BASF, Telco, Maruti Udyog Ltd., Century textile, Citibank, ACC, ANZ Grindlays, German Remedies, Blue Star, Mahindra \& Mahindra, Rallis Asian country, Sony Asian country Pvt. Ltd., Ceat Ltd., Indal, Ford Motors, Kirloskar, hillock prescribed drugs, and Glaxo. Initial tier firms (those with a turnover bigger than Rs.10 billion) implement ERP to extend internal potency and external fight. Once ERP is established at this level, these giant firms begin to need equally exaggerated potency from their suppliers. Hence, second tier firms square measure pressured to implement ERP, and a trickle-down result ensues. High-powered by the axiom that a sequence is merely as robust as its weakest link, Indian business quickly has recognized that so as to figure at most potency, ERP should be enforced in any respect levels. Initially, the bulk of ERP solutions are marketed to firms with bigger than Rs. 2 billion, and typically, consistent with business reports, the full value of deploying ERP has ranged between one and a couple of $\%$ of companies' sales. Lower value solutions square measure accessible for relatively smaller sized firms. tho' the market appears to be terribly encouraging for ERP implementation, the timeframe for preparation is also a difficulty. However, since several firms that haven't nevertheless enforced ERP square measure leaders in their markets, it moderately may be assumed that they're going to choose it inside next 5 years. In fact, the ERP market ought to grow at a rate somewhere close to the commercial rate of growth. Some business classes, like automotive, Steel, durable goods, Engineering, and Textiles have shown a awfully high ERP penetration. this implies that these classes represent the best potential markets in next 2 years different industries can follow.[30][16]

\section{ERP within the SERVICE SECTOR}

Transportation, treatment, cordial reception, traveller service, telecommunication, banking and money 
services, and amusement represent the foremost parts of India's service sector, and on inquisitor into the varied desires of those teams, it becomes apparent that the traveller, transportation, and amusement industries don't have specific current desires for ERP. Banking and telecommunication every have terribly specialised necessities that the manufacturing-inclined computer code solutions on the market wouldn't effectively address. an equivalent holds true for the treatment and cordial reception industries. The service sector has the potential to become a vital ERP market inside a couple of years. [26][28] At this point ERP implementation within the services sector is incredibly restricted solely a couple of hospitals and banks have done little scale experiments. New computer code and processes ought to be developed to satisfy the particular demands of the service industries, therefore ERP players ought to begin currently to arrange them for the tremendous potential of this future market.

\section{SMES AND ERP}

While several new SMEs begin annually, nearly five hundredth stops to exist within the initial three years of business itself. tho' it's assumed that every one SMEs need growth, solely four-hundredth survive on the far side ten years. Majority of the corporations don't consider semi permanent business strategy however focus solely on survival. They consider modification only if the business begins to fail as a results of not keeping track of the ever-changing market situation. The corporations United Nations agency survive and grow square measure those United Nations agency have the power to require risks and answer the ever-changing circumstances (Levy et al, 2006). Associate in Nursing ERP system would permit SMEs to integrate their business functions. SMEs would be ready to increase their potency and productivity by implementing an appropriate ERP system. Over successive 5 years, the ERP market in Asian country is predicted to succeed in Rs. 1,550 large integer (\$341 million), consistent with International information Corporation (IDC), a marketing research and analysis firm. Of this, the SME potential in Asian country for the enterprise category is projected to be Rs. 728 large integer $(\$ 160$ million) forty seventh of the market (Munjal, 2006). ERP vendors like SAP, Oracle, and Microsoft, QAD etc. square measure all making an attempt to extend their client base within the SME phase and have merchandise specifically designed to cater to the wants of SMEs. tho' SMEs square measure risk loth, they're keen on adopting ERP systems for many reasons. a number of them are: - Pressure from larger counterparts: because of globalisation, SMEs nowadays operate during a wider arena. Majority of them have MNCs as their shoppers. These MNCs need SMEs to implement an equivalent ERP system as them to permit for tighter integration in their provide chain, which allows them to style and arrange the assembly and delivery therefore on scale back the turnaround. - Peer pressure: many SMEs square measure adopting ERP systems as their peers have done therefore. - To realize competitive advantage and respond quickly to the dynamic market situation.

- E-commerce profits: This benefit can accrue from the shut integration between giant enterprises and SMEs. - Cheaper and quicker web: Easier access to Internet reduces the prices more. - Cheaper hardware and software: With the advances in technology, the prices of each hardware within the style of servers, cables, switches etc. and computer code like databases have come back down.[18][19]

\section{CRITICAL SUCCESS FACTORS FOR ERP ADOPTION}

Nah et al. (2006) investigated vital success factors for ERP implementation by conducting a literature review. They found that key structure problems were cooperation, change, management, high management support, arrange and vision, business method management and development, project management, monitoring, effective communication, computer code development and testing, the role of the project champion and acceptable business and IT heritage systems. Their study shows that the complicated structure modification problems should be comprehensively addressed which they cannot be overcome by mistreatment technical solutions alone. Similarly, Huang et al. (2003) counsel that additionally to developing the technical aspects of ERP, a lot of effort is needed in understanding the a lot of complicated structure problems concerned.[20] though the ERP systems are increasingly developed over a minimum of a decade, the continual pace of modification in organizations and their environments has resulted in complicated technical structure, cultural and political problems that have created the mixing method a awfully difficult task (Huang et al., 2003). In response to ERP systems implementation problems, there square measure some tutorial journals that have unconcealed specific metrics for ERP implementation success. Somers and Viscount Nelson (2004) square measure well-known joined of the 
highest 'guru' of ERP implementation United Nations agency came up with the unified vital success issue model for the industries in us. Their analysis work has received high variety of citation within the literature and might be valid from the scientific discipline citation index (SSCI) platform. Except for that, from analysis perspective, usage of a valid study that has been printed by Somers and Viscount Nelson has been accustomed kind the structure of this study. The thought is to check [23][26] the model/factors projected by these authors and see if it's applicable within the context of a developing country i.e. India.

\section{IMPACT OF THE PROPOSED RESEARCH WORK ON ACADEMICS / INDUSTRY}

Study can have necessary sensible and analysis implications. The key findings of this study would be of import to the management of the Indian little and medium enterprises (SMEs) corporations once taking selections concerning the adoption of ERP. Moreover, it provides info systems researchers and ERP consultants with higher understanding concerning the adoption of ERP systems within the context of developing countries like Asian country to confirm in implementation of ERP. It, however, ought to be acknowledged that since this analysis emerges from Associate in Nursing in-depth single-case study, the power to generalize the findings is restricted. The findings of the study square measure expected to be a lot of transferable inside the context of Indian SMEs generally. what is more it will also give a benchmark to more enhance the analysis scope of Indian ERP implementation among academicians and researchers.

\section{REFERENCES}

1. Gattiker, T. F. and Goodhue, D. L. (2005) What Happens after ERP Implementation: Understanding the Impact of Interdependence and Differentiation on Plant-level Outcomes, MIS Quarterly, 29, 3, 559-585.

2. Wright, S. and Wright A. M. (2002) Information System Assurance for Enterprise Resource Planning Systems: Unique Risk Considerations, Journal of Information Sciences, 16, 99-113.

3. Gordon, A (2006) ERP Applications: Myth and Misconceptions, Ezine Articles

4. www.ezinearticles.com, December 14

5. Mabert, V. A., Soni, A. and Venkataramanan, M.A. (2003) Enterprise Resource Planning:
Managing the Implementation Process, European Journal of Operational Research, 146, 302-314

6. Levy Margi, Powell Philip, (2006), "Strategies for growth in SMEs: The role of Information and Information Systems", Information Processing and Management: an International Journal. Vol 42

7. Nah, F. and Delgado, S. (2006) Critical Success Factors for ERP Implementation and

8. Upgrade, Journal of Computer Information Systems, 46, 5, 99-113.

9. Huang, A. D. Yen, Chou D. and Xu Y. (2003) Corporate Applications Integration: Challenges, Opportunities, and implementation Strategies, Journal of Business and Management, 9, 2, 137145.

10. Zviran, M., Pliskin, N., and Levin, R. 'Measuring User Satisfaction and Perceived usefulness in the ERP Context.' Journal of Computer Information Systems, Vol. 45, (3),

11. Spring 2005, pp 43-52.

12. Bajwa, D. S., and Garcia, J. E., 'An Integrative Framework for the Assimilation of Enterprise Resource Planning Systems: Phases, Antecedents, and Outcomes'. Journal of

13. Computer Information Systems, Vol. 44, (3), Spring 2004, pp 81-90.

14. Gulledge, T. R., and Sommer, R. 'Splitting the SAP Instance: Lessons on Scope and Business Processes,' Journal of Computer Information Systems, Vol. 44, (3), spring 2004, pp 109-115.

15. Parr, A. and Shanks, G. 'Critical Success factors Revisited: A Model for ERP Project Implementation'. In Shanks, G., Seddon, P. and Will cocks, L. (Eds.) Second-Wave Enterprise Resource Planning Systems: Implementing For Effectiveness. Cambridge University Press, Cambridge, 2003.

16. Somers, T. M., and Nelson, K. 'The Impact of Critical Success Factors across the Stages of Enterprise Resource Planning Implementations'. Proceedings of the 34th Hawaii

17. International Conference on System Sciences (HICSS-3) Maui, Hawaii. (CD-ROM), January 36, 2001,

18. Akkermans, H., and Van Helden, K. 'Vicious and virtuous cycles in ERP implementation: a case 
International Journal of Trend in Scientific Research and Development (IJTSRD) ISSN: 2456-6470 | IF: 4.101

study of interrelations between critical success factors'. European Journal of Information Systems, 11, 2002, pp 35-46.

19. Luo, W. and Strong, D. M. A Framework for Evaluating ERP Implementation Choices, IEEE Transactions on Engineering Management, Vol. 51, No 3., pp322-333 August 2004

20. Gefen, D., 'what makes an ERP implementation relationship worthwhile: Linking Trust Mechanisms and ERP Usefulness'. Journal of Management Information Systems, Vol., 21. No. 1. pp 263-288, Summer 2004

21. Sarker, S, and Lee, A. 'Using a case study to test the role of three key social enablers in ERP implementation'. Information \& Management. 40, 813-829., 2003

22. Weston, F. C. 'ERP Implementation and Project Management'. Production and Inventory Management Journal. Vol.42, Issue3/4,pp 75-80, 2001

23. Somers, T. M. and Nelson, K. G. (2004) A Taxonomy of Players and Activities across

24. The ERP Project Life Cycles, Information and Management, 41, 257-278.
25. Karimi, E. M. (2008) Enterprise ResourcePlanning Systems Adoption in Bahrain:

26. Motives, Benefits and Barriers, Journal of Enterprise Information Management 21, 3, 310334.

27. A. Amid, M. Moalagh, and A. Z. Ravasan, "Identification and classification of ERP critical failure factors in Iranian industries," Information Systems, vol. 37, pp. 227-237, 2012.

28. L. Shaul and D. Doron Tauber, "CSFs along ERP life-cycle in SMEs: a field study," Industrial Management \& Data System, vol. 112, no. 3, pp. 360-384, 2012.

29. Ansari, Z. N., \& Kant, R. Exploring the Framework Development Status for Sustainability in Supply Chain Management: A Systematic Literature Synthesis. Business Strategy and the Environment. 2017.

30. Carvalho, H. L., \& Guerrini, F. M. Reference model for implementing ERP systems: an analytical innovation networks perspective. Production Planning \& Control, 1-14. 2017. 